\title{
PRODUÇÃO DE SENTIDOS EM UM GRUPO REFLEXIVO PARA HOMENS AUTORES DE VIOLÊNCIA
}

\author{
PRODUCCIÓN DE SIGNIFICADOS EN UN GRUPO REFLEXIVO PARA \\ HOMBRES AUTORES DE VIOLENCIA
PRODUCTION OF MEANINGS IN A REFLEXIVE GROUP FOR MALE PERPETRATORS OF VIOLENCE

\author{
Victor Hugo Belarmino ${ }^{1}$ e Jáder Ferreira Leite ${ }^{1}$ \\ ${ }^{1}$ Universidade Federal do Rio Grande do Norte, Natal/RN, Brasil
}

RESUMO: Objetivou-se analisar o cenário de produção de sentidos em um grupo reflexivo para homens autores de violência conjugal: posicionamentos, dificuldades e efeitos que o grupo suscita em seus diferentes atores - homens e facilitadoras. Para tanto, foi realizada observação participante durante 10 sessões, com registros em diário de campo. A posteriori realizaram-se entrevistas semiestruturadas com dois integrantes do grupo e as profissionais condutoras. De modo geral, o grupo demonstrou ser um ambiente propício de produção, circulação e atualização de repertórios discursivos sobre o fenômeno da violência de gênero. No entanto, estes deslocamentos discursivos não acontecem de forma homogênea, tampouco sem dificuldades e tensões. O campo e os dados das entrevistas revelaram dificuldades provenientes de diferentes ordens: tanto operacional/metodológicas, institucional/burocráticas, mas, sobretudo, acerca do vínculo profissionais/homens por este se sustentar por um frágil "acordo judicial”.

PALAVRAS-CHAVE: Produção de sentido; Homens autores de violência; Grupo reflexivo; Interanimação dialógica.

RESUMEN: El objetivo de este artículo fue analizar el escenario de producción de significados en un grupo reflexivo de hombres autores de violencia conyugal: posiciones, dificultades y efectos que tiene el grupo sobre sus diferentes actores - hombres y facilitadores. Para eso, se realizó observación participante durante 10 sesiones, con registro en un diario de campo. Posteriormente, se realizaron entrevistas semiestructuradas con dos miembros del grupo y los profesionales directores. En general, el grupo resultó ser un entorno propicio para la producción, circulación y actualización de repertorios discursivos sobre el fenómeno de la violencia de género. Sin embargo, estos desplazamientos discursivos no ocurren de manera homogénea, tampoco sin dificultades y tensiones. El campo y los datos de las entrevistas revelaron dificultades derivadas de diferentes órdenes: tanto operacional/metodológico, institucional/burocrático, pero, sobre todo, acerca del vínculo profesional/masculino porque se sustenta en un frágil "acuerdo judicial”.

PALABRAS CLAVE: Producción de significado; Hombres autores de violencia; Grupo reflexivo; Interanimación dialógica.

ABSTRACT: This article aimed to analyze the scenario of production of meanings in a reflexive group for men who committed conjugal violence: the positioning, difficulties and effects the group has in its different actors - men and facilitators. For this, 10 sessions of participative observation were made, being reported on a field journal, as well as semi-structured interviews with two group members and the conductive professionals. Generally, the group has shown itself to be propitious for the production, circulation and update of discursive repertoires on the gender violence phenomena. However, these discursive movements do not happen in a homogeneous form, nor without struggles and tensions. The fieldwork and the data from the interview revealed difficulties of different orders: operational/ methodological, institutional/bureaucratic, but, above all, on the professional/men bond as it is sustained by a fragile "judicial agreement".

KEYWORDS: Meaning production; Male perpetrators of violence; Reflexive group; Dialogical inter-animation. 


\section{Introdução}

Os grupos reflexivos para homens autores de violência (HAV) contra as mulheres são projetos recentes, sobretudo em âmbito nacional. Segundo Lima e Büchele (2011), as primeiras iniciativas surgiram nos Estados Unidos na década de 70, e mais recentemente no Brasil e na América Latina nas décadas de 80 e 90. Estas primeiras intervenções normalmente eram realizadas por ONGs, por meio de financiamentos de organizações internacionais, algumas vezes em cooperação com os estados ou municípios. Em âmbito nacional, somente a partir da promulgação da Lei n. 11.340/2006 (Lei Maria da Penha: LMP), em seus artigos 35 e 45, foram institucionalizados os serviços de responsabilização aos HAV como parte integrante do Programa de Enfrentamento à Violência contra a Mulher. Já em 2020, é sancionada a Lei n. 13.984/2020, que altera o artigo 22 da LMP e pauta como medida protetiva de urgência o comparecimento obrigatório dos "agressores" aos centros de educação e de reabilitação e acompanhamento psicossocial.

Esses dispositivos legais têm impulsionado iniciativas governamentais para a abertura de novas turmas através de órgãos públicos, em sua grande parte ligadas aos tribunais de justiça ou em parceria com esses, como o Ministério Público e os equipamentos de assistência social (Beiras, Nascimento, \& Incrocci, 2019). O projeto de Natal intitulado "Homens por uma atitude de paz" é um desses exemplos e vem, desde 2012, desempenhando por meio do Núcleo de Apoio à Mulher Vítima de Violência Doméstica e Familiar (NAMVID) grupos reflexivos para homens através da LMP.

No entanto, apesar de serem iniciativas previstas e incentivadas pela LMP, ainda têm sido recebidas com desconfiança, uma vez que persistem questionamentos acerca de seu grau de eficácia, predomina a visão de que a prisão dos homens é o dispositivo que pode melhor responder à segurança das mulheres, bem como o entendimento de que representam um desvio de atenção e de recursos, os quais poderiam estar sendo direcionados às mulheres, como apontam Lima e Büchele (2011) e Lago, Ramos e Bragagnolo (2010). Na contramão destes julgamentos, algumas críticas têm sido elaboradas no sentido de fortalecer estratégias alternativas ao tradicional paradigma penal de encarceramento, tal como acontece na atualidade nos sistemas judiciário e penal. Como assertivamente apontam Soares e Gonçalves (2017): "é sabido que as instituições penais, partindo da ideia de 'punição exemplar', em vias de fato, não produzem ressocialização” (p. 132).

Ou seja, nota-se um quadro de expansão e progressivo reconhecimento destas iniciativas ao longo dos últimos anos e, consequentemente, da emergência de estudos e de debates nesse campo que se debruçam a contextualizar e avaliar tais intervenções: qual seu lugar institucional; quais metodologias, estratégias e critérios de avaliação podem ser utilizados para definir seu grau de eficácia; quais princípios e diretrizes norteiam os profissionais em suas intervenções; o que se pretende com os grupos reflexivos; as principais dificuldades que persistem tanto na prática de pesquisa, quanto da atuação neste campo; bem como aspectos teórico-conceituais (Andrade, 2014; Antezana, 2012; Acosta \& Bronz, 2014; Acosta, Andrade, \& Bronz, 2004; Beiras, 2014; Beiras \& Cantera, 2014; Beiras, Nascimento, \& Incrocci, 2019; Bernardes \& Mayorga, 2017; Billand \& Paiva, 2017; Lima \& Büchele, 2011; Medrado \& Lyra, 2014; Medrado, Lemos, \& Brasilino, 2011 ; Monteiro, 2014; Nothaft \& Beiras, 2019; Oliveira et al., 2009; Prates \& Alvarenga, 2014; Rifiotis, 2008; Soares, 2011 ; Toneli, Beiras, \& Ried, 2017). 
Um aspecto que merece ser melhor analisado nesse campo de estudos consiste nas interações que se desenvolvem nestes grupos: de que forma os(as) profissionais facilitadores(as) e os homens que experienciam o grupo produzem/transformam sentidos e se interanimam dialogicamente. Portanto, objetivamos analisar comparativamente: (a) a experiência com o grupo - os efeitos pretendidos e alcançados pelo grupo, as dificuldades experienciadas/operacionalizadas e como subjetivamente dimensionam o grupo como agenciador de transformações nas relações cotidianas; e (b) os processos de interanimação dialógicas entre homens e facilitadoras, isto é, os diferentes posicionamentos, estratégias de negociações, dialogicidade, atravessamentos de gênero e relações de poder.

A proposta de investigação a partir da produção de sentidos segue filiação à corrente do Construcionismo Social, tal com aparece no campo da Psicologia Social, segundo Spink e Freeza (2013) e Spink e Medrado (2013). A produção de sentidos é, desse modo, uma forma de conhecimento que se gera no cotidiano das interações sociais, por meio das práticas discursivas. Nessa abordagem, a linguagem se coloca como um importante articulador de produção de sentidos: uma prática social, com efeito performático, tomada em termos de suas condições de uso e de produção em determinado contexto social. A linguagem em uso diz sobre as maneiras a partir das quais as pessoas produzem sentidos e se posicionam em relações sociais cotidianas, permitindo compreender o campo das ressignificações, das rupturas, portanto, da heterogeneidade (Spink \& Freeza, 2013, p. 45), e é sobre esse aspecto que procuramos problematizar neste artigo.

\section{Considerações metodológicas}

Utilizamos como estratégias de produção de dados a observação participante em um grupo reflexivo para homens autores de violência, durante 10 sessões, com registros em diário de campo. A formatação do grupo não esteve a cargo do pesquisador, ou seja, tratava-se de uma intervenção já estruturada pelo serviço - por isso o quantitativo de dez homens e dez encontros -, e as temáticas estavam previamente incluídas no esquema estruturado pelas profissionais. O intuito em participar deste momento foi observar os processos de negociação de sentidos, as performances, os posicionamentos e os sentidos das relações de poder que possam emergir nesses encontros, bem como estruturar um roteiro de entrevista a partir da experiência no grupo.

Participaram da pesquisa de campo dez homens processados pela Lei Maria da Penha, os quais compuseram o grupo reflexivo e duas mulheres facilitadoras, uma psicóloga e uma assistente social. A etapa de campo ocorreu no segundo semestre de 2017. Após a finalização dos encontros foram realizadas entrevistas semiestruturadas com as facilitadoras e alguns homens participantes, totalizando 04 entrevistas: 2 homens e 2 profissionais. A análise dos dados foi realizada a partir da análise de conteúdo, na modalidade Análise Temática (Minayo, 2010), ancorada no construcionismo social e nos estudos sobre gênero e masculinidade, especificamente aqueles concernentes ao trabalho com homens autores de violência. 


\section{Resultados e discussão}

A apresentação dos resultados e discussões será organizada em quatro partes: na primeira, apresentando os participantes e o próprio campo, registrando as principais impressões ao adentrarem o grupo; na sequência, exploraremos os sentidos acerca da missão do grupo - aqui procuraremos observar de que modo o entendimento sobre o grupo posiciona e reposiciona os participantes em suas interações cotidianas; em terceiro, abordaremos as principais dificuldades identificadas no grupo, a partir de distintas perspectivas - incluindo a dos pesquisadores; e, por fim, exploraremos os principais efeitos observados pelos participantes em diferentes dimensões de suas vidas, após terem passado pela intervenção.

Como já mencionamos, o grupo é vinculado ao Ministério Público do estado do RN e engloba homens processados via Lei Maria da Penha, por meio de transações penais e, mais recentemente, como recurso associado às medidas cautelares e protetivas à mulher. Portanto a participação no grupo tem caráter obrigatório. O grupo é facilitado por duas mulheres: uma assistente social e uma psicóloga, e conta ainda com o auxílio de uma estagiária. Consiste em dez encontros, de frequência semanal, com duas horas de duração cada, e aborda diversas temáticas, tais como gênero, violência contra a mulher, estilos comunicacionais, agressividade e resolução de conflitos, uso de drogas, paternidade, saúde do homem, dentre outros.

Passados alguns meses desde a participação nos encontros, contamos com a colaboração de dois homens integrantes deste ciclo do grupo - Neymar e Pelé -, bem como das facilitadoras - Marta e Cristiane -, para conversarem sobre esta experiência e aprofundar alguns pontos que haviam chamado a atenção, tanto a partir da bibliografia, mas, principalmente, a partir das afetações que o campo havia suscitado. Infelizmente, não pudemos contar com a colaboração de todos que fizeram parte do grupo, o que é compreensível, haja vista o sentido comumente atribuído ao grupo: como uma punição, o que pareceu distanciá-los de revisitar a experiência de participação a posteriori. Pelé e Neymar reforçam essa tese ao significarem o grupo como sendo uma obrigação ou sentença, apesar de ambos terem avaliado como uma boa experiência, no decorrer dos encontros:

Rapaz, no primeiro encontro eu entrei com raiva, com desgosto. E se sentindo discriminado, porque, queira quer, não queira, é uma sentença. No meu caso, assim, eu sei que discutimos, a gente brigou, mas coisa que eu tava leigo... Então, tava me sentindo injustiçado, porque eu acredito que você pode ser julgado por uma coisa que você saiba. Se você não tem conhecimento daquilo, você se sente injustiçado. Mas a partir do momento que começou [o grupo], eu vi que tava errado. (Pelé, 36 anos)

Andrade (2014) confirma que o primeiro e o principal sentimento de comunhão e de vinculação ao grupo é de injustiça. Mistura (2015), por sua vez, refere que a entrada no grupo produz diferentes ordens de sentimentos como vergonha, punição, vitimização, perplexidade, estranhamento, mas também prazer, espaço de sociabilidade, escuta e interlocução, terapêutico e de elaboração e espelhamento. O grupo é colocado pelos homens como uma injustiça, na medida em que não se enxergam como agressores, bem como não reconhecem o ato que levou a denúncia como uma violência, produzindo diversos repertórios de justificação e transferência de responsabilidade à (ex) companheira ou a outrem (Prates \& Alvarenga, 2014). 
Corroborando com a fala de Pelé e Neymar, Marta expõe que é comum os homens chegarem revoltados, sentindo-se injustiçados, o que se mantém forte, sobretudo nos primeiros encontros, mas no decorrer do processo grupal estas tensões diminuem. Isto também foi observado por Prates e Alvarenga (2014), apesar de os homens apresentarem percepção negativa sobre o atendimento policial e se colocarem no lugar de vítimas, o início da participação no grupo é marcado por um "processo catártico" (p. 231).

Por mais que não observamos nas facilitadoras o intuito de criminalizar os homens integrantes, é inegável que exista todo um conjunto semiótico e discursivo cristalizado nestes equipamentos. Considerando o caráter compulsório e automático das intervenções penais, Rifiotis (2008) refere-o como um dos grandes obstáculos para os grupos reflexivos. Tal como defende Andrade (2014): o sistema jurídico, no trato do homem autor de violência inclina-se a avaliar sua periculosidade, grau ofensivo, tipificação das violências, diagnósticos e prognósticos, imprimindo sentidos muito claros a todos que adentram aquele espaço: o de culpa, reprovação moral, punição e julgamento. Isto, sem dúvida, representa um desafio importante à intervenção, se considerarmos que produzir reflexão, desconstruir velhas normas e construir novas formas de ser no mundo, inexoravelmente exige abertura e disponibilidade, o que não são conseguidos caso esses homens se sintam em um espaço condenatório.

Marta, contando um pouco sobre seu trabalho com as mulheres em outro serviço da rede de proteção à mulher, anterior ao projeto junto homens, revela que o trabalho junto aos homens, apesar de ser algo muito pontual dentro das políticas de enfrentamento, sempre foi uma necessidade que sentiu a partir do acolhimento das mulheres. Segundo Marta, em muitos casos pedia-se uma mudança de postura, e não uma punição a priori. Ademais, tal intervenção representaria uma forma de modificar padrões tradicionais de masculinidade, efeito que a simples condenação não é capaz de atingir.

Andrade (2014) corrobora com a ideia expressa por Marta. Para o autor, os mecanismos de punição e repressão têm se mostrado insuficientes na contenção do crescimento da violência contra a mulher. Ou seja, tal como situa Soares (2011), apostar em outras alternativas não consiste em promover conciliações conjugais, menosprezar medidas cautelares ou meramente sugerir diálogo, mas, como apontam Acosta e Bronz (2014), reconhecer que a maioria dos casos não inclui homens cujo grau de violência exige contenção externa absoluta, o que torna necessário analisar as nuances de cada caso e intervir nos casos em que as mulheres sofram risco de morte e ameaças à sua integridade física e psicológica.

Neste sentido, o grupo tem o potencial de transformação social em nível subjetivo, individual e das relações cotidianas (Beiras \& Cantera, 2014), mostrando-se uma alternativa concreta às soluções estritamente punitivas (Acosta, Andrade, \& Bronz, 2004), haja vista que a privação da liberdade, se levada a cabo como um "fim em si mesma", coloca-se como uma solução inadequada frente a ao amplo espectro da violência conjugal (Soares, 2011). Ademais, concordamos com Acosta, Andrade, e Bronz (2004), quando advertem ser a prisão o local privilegiado de circulação de repertórios discursivos e códigos masculinos da virilidade violenta, contexto favorável ao recrudescimento da violência. Por este motivo estes autores reafirmam o grupo como uma ação complementar, e não substitutiva de outras ações, permitindo que os homens ampliem os recursos e repertórios para resolução de conflitos. 


\section{O que compreendem como a missão do grupo}

Os homens integrantes e as facilitadoras se posicionam diversamente sobre a missão do grupo. Marta, com trajetória profissional há alguns anos junto aos HAV, representa-o como um dispositivo de "quebra de paradigmas", ou seja, de desconstrução acerca nas normas e lugares de gênero prescritos, bem como padrões violentos de interação social:

Eu diria que um dos objetivos é criar um espaço de escuta, de compartilhamento de ideias, de informações, o objetivo dele é "quebrar paradigmas", o objetivo dele é desconstruir esses "papéis de gênero", o objetivo dele é contribuir para o enfrentamento da violência... Então, na verdade, o que nós queremos é "plantar a semente": promover, de fato, a discussão e a reflexão; que eles, de fato, reflitam sobre esses assuntos. E, a partir disso, que eles possam ter uma nova postura, um novo olhar para a questão da violência contra a mulher, a violência de gênero. (Marta, 38 anos, assistente social)

Os profissionais do estudo de Monteiro (2014) também compreendem o grupo como uma possibilidade de mudança e transformação de valores, ao passo que provoca responsabilização sobre as situações de conflito e violência. Da mesma forma, Silva, Coelho e Njaine (2014) compreendem este modelo de intervenção grupal como catalisador para a desconstrução e a mudança dos padrões naturalizados de gênero, violência de gênero e formas de interação social instituídas com base no padrão de masculinidade hegemônica. Segundo esses últimos, "a perspectiva é de que o grupo sirva como parâmetro de socialização masculina em outros contextos sociais dos homens” (p. 193). Outros autores (Beiras \& Cantera, 2014; Toneli, Beiras \& Ried, 2017) também concordam com a ideia do grupo como "potencial espaço de visibilidade e desconstrução do masculino tradicional" (Beiras \& Cantera, 2014, p. 39).

Ainda de acordo com Beiras e Cantera (2014), o grupo deve oferecer "a possibilidade de construção de uma expressão do masculino na qual a violência seja questionada como aspecto formador e constituinte da subjetividade” (p. 39). Este esforço, sem dúvida, foi sentido nos encontros ao qual acompanhamos. No entanto, é necessário apontar alguns percalços vivenciados no campo, os quais são atravessadores da produção de sentidos em interação nos encontros, tais como: a cisão individualização/psicologização do objeto de trabalho conferido à psicologia e dos processos sociais ao serviço social; o desconhecimento dos homens acerca da "missão" do grupo contrastado com o entendimento de que estes objetivos autoenunciariam-se a cada encontro; a caricatura da masculinidade hegemônica nos materiais de suporte, o que impacta no reconhecimento das situações apresentadas às realidades cotidianas destes homens ou mesmo que se sintam representados nesses personagens; os mecanismos de "limpeza discursiva", quando no exercício de facilitação operam "cortes" à algumas falas contraditórias, conservadoras, polêmicas, divergentes ou conflituosas; a recusa em dar espaço às histórias de vida e do cotidiano, sob o critério de não trabalhar os casos individualmente; e a mecânica que se engrena ao cotidiano dos encontros, possivelmente relacionada à abertura de múltiplas turmas sob responsabilidade de somente duas facilitadoras, resultando em sobrecarga de trabalho.

Cristiane afirma o grupo como espaço de trocas, para o qual os homens precisariam reconhecer os atos de violência cometidos. Acerca deste sentido, podemos interpretar das seguintes formas: tanto como a ética e o olhar destes grupos resvalam para as propostas 
dos grupos terapêuticos (Andrade, 2014), quanto este produz efeitos terapêuticos, mesmo não se propondo a ser terapêutico (Acosta, Andrade, \& Bronz, 2004). Cristiane acrescenta, ainda, que - se consideradas as limitações do grupo - o intuito seria de provocar microrupturas no cotidiano e nos modos de subjetivação dos homens integrantes. De certo modo, assemelha-se ao enunciado por Marta, até pela sua trajetória mais recente no trabalho com os homens:

O objetivo é que eles entendessem que eles praticaram violência e não cometessem isso mais lá na frente, mas eu acho que, na prática, é pelo menos sensibilizá-los. Pelo menos, "plantar uma sementinha" que muitos ali chegam e não sabem nem o que é. E, às vezes, quando vai conversando, ajuda no relacionamento deles mesmo. (Cristiane, 40 anos, psicóloga)

Para Pelé, representa uma ampliação do conhecimento sobre as relações interpessoais no cotidiano. Acerca disso, refere:

Eu acredito que o objetivo maior que eu venha a ser acolhido... É, a gente poder respeitar o espaço do outro, no meu caso era o "cônjuge", né? Poder respeitar aquele espaço e tentar construir uma sociedade melhor através de algumas pequenas ações que até então eu não tinha conhecimento. A gente vê, a gente presencia, mas a gente não tem conhecimento que aquelas pequenas ações a gente pode mudar, não só o nosso convívio como um pouco da sociedade. (Pelé, 36 anos)

Corroborando com a fala de Pelé, Toneli, Lago, Beiras e Clímaco (2010) referem ser maior a eficácia do grupo se valorizado o caráter relacional e subjetivo de emergência da violência no âmbito conjugal e doméstico. Cremos que este olhar não só permite que estes homens flexibilizem noções machistas arraigadas, a exemplo da mulher como posse do homem, como também facilita que outros homens percorram o caminho feito por Pelé: de lançar um olhar "de fora" - a partir do grupo -, para "dentro" - no dia a dia em sua família.

Neymar, por sua vez, apresenta uma visão mais ampla: “mostrar que a mulher tem de ser bem tratada”. Na sequência, porém, já aproveita para realizar uma crítica ao formato do grupo, uma vez que reúne homens que cometeram diferentes tipos de violência, sendo a violência física considerada mais grave, ainda que se questionem apenas pelos excessos. Ou seja, um empurrão, segurar mais forte, puxar o cabelo, dentre outras situações mais sutis não têm o mesmo peso de bater na mulher:

Porque, assim, se você pegar um cara, como aquele senhor que saiu antes de todos, que está ali revoltado e tal, se for verdade mesmo o que ele disse, e botar um cara como aquele que disse que bateu na mulher até [desmaiar]... É meio que "radical" colocar todo mundo num lugar só. (Neymar, 38 anos)

Ou seja, quando Neymar defende ser "radical”, a turma congregar diferentes perfis de agressão, na verdade, realiza um duplo movimento: procura isentar-se de haver praticado violência contra sua ex-parceira, mas também diferenciar-se do conjunto dos outros homens ali presentes. Isso nos leva a pensar novos desafios para o trabalho junto aos homens a exemplo do reconhecimento - quando se considera outros marcadores da diferença, como de classe e de raça. Ora, Neymar destoava dos demais integrantes por usufruir de 
melhores condições de vida, além de possuir maior grau de escolaridade. Ocupar este lugar de privilégio, sem dúvida, traz implicações ao grau de abertura e à disponibilidade de reflexão em coletivo. Os resultados encontrados por Garcia e Beiras (2019) corroboram conosco ao apontar que os homens normalmente justificam e depositam a responsabilidade pela agressão em um "outro" - exterioridade que varia conforme as referências e os vínculos sociais que produzem os sentidos do ser homem. No caso de Neymar, esse "outro" tanto assume um gênero (da mulher como a culpada e provocadora), quanto uma imagem de homem que se diferencia pelo poder aquisitivo, pela escolaridade, pela cor da pele e pela ocupação.

\section{Acerca das dificuldades experienciadas}

Marta, tal como Cristiane, considera este grupo ao qual acompanhamos um dos mais complexos e difíceis de "comandar". Segundo Cristiane, a turma alvo desta pesquisa foi nomeada como "grupo dos trabalhosos", no sentido de "fugir do tradicional", ou seja, do habitual: "eles não aceitavam o que era dito" (Cristiane, 40 anos, psicóloga). Todavia, ainda que de partida houvesse contestações sobre temas como o direito das mulheres, tal como observado a seguir na fala de Pelé, conforme o decorrer dos encontros dava-se lugar à abertura de diálogo sobre o tema:

A gente se sente um pouco acuado, né? Já que a gente vai estar tratando um assunto que é referente, praticamente, que é o que foi tratado lá que são os direitos das mulheres. $E$ quando você tem uma mulher na frente você se fecha mais um pouco, mas no decorrer, como foi no meu caso, ela foi ganhando confiança, foi conversando. (Pelé, 36 anos)

Marta reconhece que pesa sobre sua imagem o papel de "agentes da justiça”, para além de serem reconhecidas como mulheres. De certo modo, corrobora com a suposição suscitada a partir de um dos encontros: de como utilizam este "poder institucional" para equilibrarem o campo de forças dentro do grupo: "Por isso eu digo que, muitas vezes, a gente está numa situação muito favorável, enquanto facilitadora, porque ali você está numa condição em que você é o 'agente dominante', então esse papel, ali, às vezes se torna um pouco confortável" (Marta, 38 anos, assistente social).

Esta fala desvela que a intersecção entre ser "mulher" e "agente da justiça" significa muito mais que a simples sobreposição de lugares: compreende o resultado de diversas trajetórias de lutas feministas, as quais ampliaram a inserção das mulheres nos espaços de saber-poder, anteriormente sobremaneira restritos aos homens. Porém, como podemos observar nas falas elaboradas pelos colaboradores desta pesquisa, a instituição justiça, com todas suas contradições, atravessa as relações que se constroem no grupo reflexivo, o que tem efeitos importantes em termos de interanimação dialógica. Ou seja, se por um lado, a instituição justiça é utilizada como peso compensador das assimetrias de poder entre homens e mulheres, por outro também pode representar uma dificuldade ao grau de abertura às falas dos homens autores de violência.

Acerca da implicação com a instituição justiça, Marta compreende que, mesmo diante das desigualdades sociais existentes entre homens e mulheres, vestir aquela "roupa institucional" a permite não apenas equalizar as relações de forças naquele espaço, 
mas inclusive inverter a norma social de hegemonia masculina, e se tornar o "agente dominante". O estudo realizado por Oliveira (2012) encontra resultado semelhante. Para as profissionais do estudo de Oliveira, o caráter obrigatório da intervenção e a facilitação do grupo realizada por mulheres representam um "efeito pedagógico deveras interessante" (2012, p. 103), na medida em que impõe respeito e confere autoridade às mulheres, as quais estiveram historicamente em posição de subalternidade. Pacheco (2014) ajuda a compreender essa prática discursiva, porquanto relaciona o processo de judicialização das relações sociais como um "vetor de subjetivação" (p. 116), em outras palavras: a implicação da instituição justiça no processo de produção de sentido no cotidiano de seus agentes e o consequente deslocamento dos tradicionais sentidos atribuídos ao gênero nestes equipamentos. Ou seja, o grupo não acontece numa arena isenta de ideias, representações e instituições. As relações de gênero atravessam e impactam nas interações desenvolvidas no grupo, mas outras instituições também atuam nas interanimações dialógicas, dentre elas a própria instituição justiça.

Pelé afirma que alguns conteúdos pareciam distantes de sua realidade social e cotidiana. Tal como observado em campo, esta fala desvela o potencial efeito negativo que os materiais de suporte ${ }^{1}$ poderiam ter, uma vez que caricaturam os lugares tradicionais, distanciando a possibilidade que os homens se reconheçam nos personagens e situações utilizadas. Ainda assim, Pelé sinaliza o potencial do grupo em agenciar espaços de fala e escuta, o que normalmente não é realizado cotidianamente:

porque quando chega, já chega com aquele desânimo, "não, tô aqui obrigado", mas do meio pro fim você sente um prazer por estar lá, estar aprendendo mais, você poder estar compartilhando alguma coisa com outras pessoas que no dia-a-dia você não iria falar... (Pelé, 36 anos)

Talvez, por este motivo, persiste a dificuldade em relação à disponibilidade de participação dos homens, ainda que se façam presentes em todos os encontros. De certa forma, isso contrasta com o que foi registrado em diário de campo: apesar de as palavras serem a ferramenta mais utilizada nos encontros, normalmente estas falas pouco se expandiam, rebatiam e eram negociadas pelo coletivo, o que se deve em parte à centralidade do formato expositivo e informativo - semelhante a uma aula ou seminário -, mas sobretudo pelo sentido produzido pelos homens em função da obrigatoriedade de participação e entendimento do grupo como uma penalização.

Até mesmo os próprios homens, porque embora eles estejam numa obrigação, eles têm de estar disponiveis. Disponíveis no sentido da "entrega", né? De vir pra cá e "estar aqui", de fato, participar. Que quando é aquele que sai: "olhe, hoje eu vou estar presente, mas não vou contribuir”, é um desafio também. (Marta, 38 anos, assistente social)

Creio que o que se desvela por meio desta fala é a qualidade do vínculo conseguido com estes homens, sustentado majoritariamente pelo frágil "acordo judicial" (Pacheco, 2014). Tal como alude Beiras (2014), a dificuldade de adesão destes homens é carregada de resistência, preconceitos e, sobretudo, pelo parco conhecimento dos equipamentos da justiça sobre o grupo, de forma a produzir um espaço pouco convidativo para falar sobre afetos e afetações, produzir novos sentidos e gerar posicionamentos discursivos diferentes em seus repertórios. Normalmente, como pudemos observar, nesse contexto 
institucional os homens se preocupam mais em afastar-se da figura de agressores do que reconhecerem sua parcela de responsabilidade nas relações violentas e repensarem seus valores. Pensar criticamente acerca da qualidade desse vínculo, sem dúvida, é um esforço potente, na medida em que as próprias relações funcionam como dispositivos concretos de desconstrução e construção de novas subjetividades: afinal, são nas interações que os sentidos ganham materialidade no cotidiano.

Apesar de trazer muitos repertórios realizados por Marta, Cristiane acrescenta um desafio interessante: da programação rígida, a qual não oferece muitas brechas de expansão dos discursos e posicionamentos. Tal rigidez também foi referida num dos diários de campo, no qual defendemos haver uma engrenagem estruturada no funcionamento do grupo, possivelmente resultante do equacionamento de alguns fatores, tanto de ordem operacional - longa lista de espera de homens aguardando serem convocados, limitado quantitativo de profissionais, poucos encontros e diversas temáticas a serem trabalhadas -; quanto de ordem afetiva, ou seja, acerca do desgaste em lidar com uma temática e campo complexos, sobretudo ao considerarmos o atravessamento das desigualdades de gênero, tensionando a cada encontro estas facilitadoras a equilibrarem as dissimetrias de poder existentes entre homens e mulheres.

\section{Efeitos no cotidiano a partir da experiência no grupo}

Apesar das dificuldades e resistências dos homens em participarem ativamente dos encontros, ao fazerem uma avaliação pessoal sobre a importância de terem participado desta intervenção, todos relataram sentir efeitos positivos em suas trajetórias de vida e em seus cotidianos, inclusive as facilitadoras. Pelé considera a participação no grupo uma oportunidade para aprender coisas novas, sobretudo acerca de como suas ações reverberam na relação familiar como um todo. Prates e Alvarenga (2014) confirmam esta fala de Pelé, situando que o processo reflexivo produz maior flexibilização, abertura e diminuição das resistências, possibilitando a "emergência de novos pensamentos e atitudes frente às temáticas” (p. 231). Corroboram Billand e Molinier (2017), afirmando que a participação destes homens no grupo confronta-os a descobrirem suas semelhanças a outros homens acusados de violência e, neste caminho, ajuda-os a repensar suas próprias relações com as mulheres, sobretudo no âmbito conjugal.

Me ajudou a parar um pouco antes de tomar qualquer decisão, ver o outro lado daquela outra pessoa que tá lá. Eu acho que um ponto é poder enxergar o que aquela outra pessoa vê. E ser mais sensivel com pequenas coisas, um "bom dia", um "boa noite", um "tudo bem", sentar, parar um pouco pra conversar. Eu relatei lá que na minha casa a gente sempre para, em meia hora, quarenta minutos a gente conversa sobre o dia a dia, mas alguns pequenos pontos a gente deixava passar. Mas a partir do momento que eu frequentei esse grupo eu vim abrindo os olhos, eu vi que foi bastante bom ter participado. (Pelé, 36 anos)

Tal como no estudo de Mistura (2015), as falas dos homens apontam para maior flexibilização nas dinâmicas familiares, vislumbrando outras possibilidades para resolução dos conflitos. Entretanto, semelhante a outros estudos com homens autores de violência, um fator que interfere na implicação desses homens consiste no não reconhecimento dos 
atos cometidos e consequente deslocamento e concentração desta responsabilidade às mulheres ou a terceiros, como encontrado no estudo de Rosa, Boing, Büchele, Oliveira, e Coelho (2008). O grupo, enquanto espaço de reflexão, tem o desafio de penetrar nas múltiplas camadas de sentidos, sentimentos e barreiras/resistências para, por fim, ter a potência de estimular novas formas de pensamento. Neste sentido, assim como Pacheco (2014), acreditamos que a "semente" que precisa ser plantada nesses homens, levando em conta o curto tempo da intervenção, é o da dúvida, e não apenas apresentar novos regimes de verdade.

Cristiane confessa que fazer parte desta ação junto aos homens contribuiu para desconstruir estereótipos que ela própria tinha quanto aos homens que cometiam violência conjugal, antes de fazer parte da equipe:

eu cheguei com algumas ideias preconceituosas, tipo: "o homem é o que pratica violência doméstica, é violento, ele não presta...", eu cheguei com esse pensamento. E com o decorrer eu vi que não. Não estou eximindo a culpa, mas se ele comete, não significa que ele é violento, que ele vai ser um agressor sempre. (Cristiane, 40 anos, psicóloga)

Tal como encontrado no estudo realizado por Oliveira (2012), também foi observada a desconstrução do sentido estereotipado normalmente atribuído aos homens autores de violência, enquanto agressores por excelência. Alguns autores (Granja \& Medrado, 2009; Lima \& Büchele, 2011; Rosa et al., 2008) compreendem que a expressão "agressores" acaba por reduzir o autor ao ato, razão pela qual tal categoria é vista como insustentável, e mais obscurecem uma melhor compreensão e intervenção nos casos de violência do que contribuem para o efetivo enfrentamento. No entanto, como apontam Granja e Medrado (2009), a desconstrução desta forma de compreensão tem sido difícil de realizar, sobretudo pelo receio que se tem de minimizar o ato cometido pelos homens. Na contramão desse receio, Soares (2011) situa a importância de enxergar o fenômeno da violência sem produzir subjetividades unívocas, imunes a contradições, porosidades, tensões e ambivalências.

\section{Considerações finais}

De modo geral, o grupo demonstrou ser um ambiente propício de produção, circulação e atualização de repertórios discursivos sobre as relações de gênero e das formas de significação sobre a violência contra as mulheres: alguns homens conseguiram traduzir as reflexões feitas em grupo para suas relações cotidianas, de certo modo, flexibilizando algumas noções arraigadas com base numa masculinidade tradicional. No entanto, como as impressões conseguidas a partir da participação em campo e também os dados das entrevistas revelaram, estes deslocamentos discursivos não foram homogêneos, nem aconteceram sem dificuldades e tensões, como foi problematizado: em razão de uma série de fatores, tanto de ordem operacional/metodológicas, quanto institucional/burocráticas mas, sobretudo, de ordem relacional/afetiva.

Metodologicamente, um desafio que se impôs foi explorar diversos temas transversais às masculinidades no tempo disponível de duração da intervenção. Neste caso, uma possível saída pode ser focar nos aspectos diretamente relacionados às desigualdades e às violências de gênero. Tal condensação de conteúdos pode - e deve - vir atrelada à maior 
abertura de canais dialógicos, espaços onde as falas dos homens tenham oportunidade de se expandirem e serem negociadas pelo coletivo. Um exemplo disso é a proposta metodológica desenvolvida pelo Instituto Noos ancorada no construcionismo social, a qual ressalta "a importância do enfoque na relação, na narrativa e na produção de processos reflexivos nas práticas grupais e comunitárias, onde cada participante de um grupo traz para o processo relacional sua história prévia, suas posições, sua compreensão das experiências vividas" (Beiras \& Bronz, 2016, p. 26).

Ademais, tal como defende Prates e Alvarenga (2014), é possível alcançar bons resultados nestas intervenções, desde que sejam mantidas algumas condições, a saber: garantir seu caráter socioeducativo; articular à abordagem de gênero; oferecer capacitações aos profissionais; possuir diretrizes mais detalhadas; ganhar caráter efetivo de política pública; garantir seu funcionamento em rede, e não como atividades isoladas/fragmentadas; e, por fim, que sejam estruturadas estratégias padronizadas de avaliação contínua. Acosta e Bronz (2014) acrescentam que as metodologias precisam ser pensadas a longo prazo, tornando possível verificar a amplitude do impacto dos grupos de reflexão.

Um dos desafios que merece ser levado em conta para a realidade local do trabalho com HAV, mas que também é sinalizado por outros autores (Andrade, 2014; Amado, 2017), diz respeito ao investimento em indicadores para avaliação do pós-grupo. De acordo com Amado, os índices oficiais de reincidência são insuficientes para demonstrar a eficácia da intervenção, fazendo-se necessário ampliar a noção de reincidência. Andrade, por sua vez, situa que, por melhores que sejam os indicadores durante o processo grupal, é fundamental construir outras ferramentas e dispositivos de acompanhamento. Uma das tecnologias que acreditamos ser válida neste sentido são as visitas domiciliares, uma estratégia de aproximação da realidade social desses homens e de suas famílias que já vinha sendo desempenhada pelas profissionais, mas que merece ser ampliada e consolidada no rol de atividades desempenhadas pela equipe.

\section{Nota}

1 Majoritariamente recortes de papel com falas ou imagens, bem como exposição de vídeos - escolhidos de outras intervenções que trabalham com grupos reflexivos, a exemplo do curta-metragem "Não é fácil, não", elaborado pelo Promundo e o Instituto Noos. 


\section{Referências}

Acosta, F. \& Bronz, A. (2014). Desafios para o trabalho com homens em situação de violência com suas parceiras íntimas. In E. A. Blay (Org.), Feminismos e masculinidades: novos caminhos para enfrentar a violência contra a mulher (pp. 139-148). São Paulo: Cultura Acadêmica. Acosta, F., Andrade, A., \& Bronz, A. (2004). Conversas homem a homem: grupo reflexivo de gênero: metodologia. Rio de Janeiro: Instituto Noos.

Amado, R. M. (2017). O que fazer com os homens autores de violência contra as mulheres? Uma análise sobre os serviços destinados aos homens processados pela Lei Maria da Penha. In A. Beiras \& M. Nascimento (Orgs.), Homens e violência contra mulheres (pp. 216-238). Rio de Janeiro: Instituto Noos.

Andrade, L. F. (2014). Grupos de homens e homens em grupos: novas dimensões e condições para as masculinidades. In E. A. Blay (Org.), Feminismos e masculinidades: novos caminhos para enfrentar a violência contra a mulher (pp. 173-210). São Paulo: Cultura Acadêmica.

Antezana, A. P. (2012). Intervenção com Homens que praticam violência contra seus cônjuges: reformulações teórico-conceituais para uma proposta de intervenção construtivista-narrativista com perspectiva de gênero. Nova Perspectiva Sistêmica, 42, 9-27.

Beiras. A. (2014). Relatório mapeamento de serviços de atenção grupal a homens autores de violência contra mulheres no contexto brasileiro. Rio de Janeiro: Instituto Noos \& Instituto Promundo.

Beiras, A. \& Bronz, A. (2016). Metodologia de grupos reflexivos de gênero. Rio de Janeiro: Instituto Noos.

Beiras, A. \& Canteira, L. M. (2014). Feminismo pós-estruturalista e masculinidades: contribuições para a intervenção com homens autores de violência. In E. A. Blay (Org.), Feminismos e masculinidades: novos caminhos para enfrentar a violência contra a mulher (pp. 29-44). São Paulo: Cultura Acadêmica.

Beiras, A., Nascimento, M., \& Incrocci, C. (2019). Programas de atenção a homens autores de violência contra as mulheres: um panorama das intervenções no Brasil. Saúde e Sociedade, 28(1), 262-274.

Bernardes, J. P. \& Mayorga, C. (2017). Um Estudo Sobre Intervenções Junto a Homens Autores de Violência Doméstica Contra Mulheres. Revista de Psicología (Santiago), 26(1), 133147.

Billand, J. \& Molinier, P. (2017). O trabalho da masculinidade: exigências subjetivas da facilitação e da pesquisa em um grupo reflexivo para homens autores de violência contra mulheres. In A. Beiras \& M. Nascimento (Orgs.), Homens e violência contra mulheres (pp. 140-171). Rio de Janeiro: Instituto Noos.

Billand, J. \& Paiva, V. S. F. (2017). Desconstruindo expectativas de gênero a partir de uma posição minoritária: como dialogar com homens autores de violência contra mulheres? Ciência \& Saúde Coletiva, 22(9), 2979-2988.

Garcia, A. L. C., \& Beiras, A. (2019). A Psicologia Social no Estudo de Justificativas e Narrativas de Homens Autores de Violência. Psicologia: Ciência e Profissão, 39(n.spe2), e225647. Granja, E. \& Medrado, B. (2009). Homens, violência de gênero e atenção integral em saúde. Psicologia \& Sociedade, 21(1), 25-34. https://doi.org/10.1590/S0102-71822009000100004

Lago, M. C. S., Ramos, M. E., \& Bragagnolo, R. I. (2010). Enfrentamento da violência doméstica e familiar na legislação brasileira: Lei Maria da Penha. In M. J. F. Toneli, M. C. S. Lago, A. Beiras, \& D. A. Clímaco (Orgs.), Atendimento a homens autores de violência contra as mulheres: experiências latino americanas (pp. 25-47). Florianópolis: UFSC/CFH/NUPPE. 
Lima, D. C. \& Büchele, F. (2011). Revisão crítica sobre o atendimento a homens autores de violência doméstica e familiar contra as mulheres. Physis: Revista de Saúde Coletiva, 21(2), 721-743.

Lei n. 11.340, de 07 agosto de 2006. (2006). Cria mecanismos para coibir a violência doméstica e familiar contra a mulher e dá outras providências. Brasília, DF: Presidência da República. Recuperado de http://www.planalto.gov.br/ccivil_03/_ato2004-2006/2006/lei/111340.htm

Lei n. 13.984, de 3 de abril de 2020. (2020). Altera o art. 22 da Lei n. 11.340, de 7 de agosto de 2006 (Lei Maria da Penha), para estabelecer como medidas protetivas de urgência frequência do agressor a centro de educação e de reabilitação e acompanhamento psicossocial. Recuperado de http://www.planalto.gov.br/ccivil 03/ ato2019-2022/2020/lei/L13984.htm

Medrado, B., Lemos, A. R., \& Brasilino, J. (2011). Violência de gênero: paradoxos na atenção a homens. Psicologia em Estudo, 16(3), 471-478.

Medrado, B. \& Lyra, J. (2014). Princípios ou simplesmente pontos de partida fundamentais para uma leitura feminista de gênero sobre os homens e as masculinidades. In E. Blay (Org.), Feminismos e masculinidades: novos caminhos para enfrentar a violência contra a mulher (pp. 55-74). São Paulo: Cultura Acadêmica

Minayo, M. C. S. (2010). O desafio do conhecimento: pesquisa qualitativa em saúde. São Paulo: HUCITEC.

Mistura, T. F. (2015). Vivência de homens autores de violência contra a mulher em grupo reflexivo: memórias e significados presentes. Dissertação de Mestrado, Programa de Pós-graduação em Saúde Pública, Faculdade de Saúde Pública, Universidade Federal de São Paulo, SP. Recuperado de https://sucupira.capes.gov.br/sucupira/public/consultas/coleta/trabalhoCon$\underline{\text { clusao/viewTrabalhoConclusao.jsf?popup }=\text { true\&id trabalho }=2424765}$

Monteiro, A. C. (2014). Autores de violência doméstica e familiar: um estudo sobre um grupo de reflexão no Paranoá/DF. Dissertação de Mestrado, Programa de Pós-graduação em Sociologia, Instituto de Ciências Sociais, Universidade de Brasília, Brasília, DF. Recuperado de http:// repositorio.unb.br/handle/10482/16164

Nothaft, R. J. \& Beiras, A. (2019). O que sabemos sobre intervenções com autores de violência doméstica e familiar? Revista Estudos Feministas, 27(3), e56070.

Oliveira, A. E. C. (2012). Atendimento a homens autores de violência contra a mulher: lacunas, desafios e perspectivas. Dissertação de Mestrado, Programa de Pós-graduação em Estudos Interdisciplinares Sobre Mulheres Gênero e Feminismo, Faculdade de Filosofia e Ciências Humanas, Universidade Federal da Bahia, Salvador, BA. Recuperado de https://repositorio.ufba. br/ri/bitstream/ri/7778/1/Disserta $\% \mathrm{C} 3 \% \mathrm{~A} 7 \% \mathrm{C} 3 \% \mathrm{~A} 3 \mathrm{o} \% 20 \mathrm{Mestrado} \% 20-\% 20$ Anderson $\% 20$ Eduardo\%20Carvalho\%20de\%20Oliveira.pdf

Oliveira, J. B., Lima, M. C. P., Simão, M. O., Cavariani, M. B., Tucci, A. M., \& KerrCorrêa, F. (2009). Violência entre parceiros íntimos e álcool: prevalência e fatores associados. Revista Panamericana de Salud Pública, 26(6), 494-501.

Pacheco, B. F. S. (2014). Masculinidade, performatividade e precariedade. Dissertação de Mestrado, Programa de Pós-graduação em Psicologia, Instituto de Psicologia, Universidade Federal do Rio de Janeiro, RJ. Recuperado de https://sucupira.capes.gov.br/sucupira/public/ consultas/coleta/trabalhoConclusao/viewTrabalhoConclusao.jsf?popup=true\&id trabal$\underline{\mathrm{ho}=1317989}$

Prates, P. L. \& Alvarenga, A. T. (2014). Grupos reflexivos para homens autores de violência contra a mulher: sobre a experiência na cidade de São Paulo. In E. A. Blay (Org.), Feminismos e masculinidades: novos caminhos para enfrentar a violência contra a mulher (pp. 225-246). São Paulo: Cultura Acadêmica.

Rifiotis, T. (2008). Judiciarização das relações sociais e estratégias de reconhecimento: repensando a 'violência conjugal' e a 'violência intrafamiliar'. Revista Katálysis, 11(2), 225-236. 
Rosa, A. G., Boing, A. F, Büchele, F., Oliveira, W. F., \& Coelho, E. B. S. (2008). A violência conjugal contra a mulher a partir da ótica do homem autor da violência. Saúde Soc., 17(3), 152-160.

Silva, A. C. L. G., Coelho, E. B. S., \& Njaine, K. (2014). Violência conjugal: as controvérsias no relato dos parceiros íntimos em inquéritos policiais. Ciência \& Saúde Coletiva, 19(4), 1255 1262.

Soares, B. M. (2011) A “conflitualidade" conjugal e o paradigma da violência contra a mulher. Revista de Estudos de Conflito e Controle Social, 5(2), 191-210.

Soares, C. T. \& Gonçalves, H. S. (2017). O macho, o covarde e o criminoso: alguns comentários sobre o processo de criminalização da violência contra a mulher no Brasil. In A. Beiras \& M. Nascimento (Orgs.), Homens e violência contra mulheres (pp. 114-139). Rio de Janeiro: Instituto NOOS.

Spink, M. J. \& Freeza, R. M. (2013). Práticas discursivas e produção de sentido: a perspectiva da psicologia social. In M. J. Spink (Org.), Práticas discursivas e produção de sentidos no cotidiano (pp. 1-21). Rio de Janeiro: Editora Cortez.

Spink, M. J. P. \& Medrado, B. (2013). Produção de sentido no cotidiano: Uma abordagem teórico-metodológica para análise das práticas discursivas. In M. J. P. Spink (Org.), Práticas Discursivas e Produção de Sentidos no Cotidiano: Aproximações Teóricas e Metodológicas (pp. 22-41). São Paulo: Editora Cortez.

Toneli, M. J. F., Lago, M. C. S., Beiras, A., \& Clímaco, D. A. (2010). Atendimento a homens autores de violência contra as mulheres: experiências latino americanas. Florianópolis: UFSC/ $\mathrm{CFH} / \mathrm{NUPPE}$.

Toneli, M., Beiras, A., \& Ried, J. (2017). Homens autores de violência contra mulheres: políticas públicas, desafios e intervenções possíveis na América Latina e Portugal. Revista de Ciências Humanas, 51(1), 174-193.

\section{VICTOR HUGO BELARMINO \\ http://orcid.org/0000-0002-4102-3351}

Departamento de Psicologia, Psicologia Social, Universidade Federal do Rio Grande do Norte

Endereço: Rua José Seabra, n. 302 1, Capim Macio, Natal/RN, CEP 59.078.510.

E-mail: victorbelarmino@,outlook.com

\section{JÁDER FERREIRA LEITE}

https://orcid.org/0000-0002-6045-531X

Departamento de psicologia, psicologia social. Universidade Federal do Rio Grande do Norte

E-mail: jaderfleite@gmail.com 


\begin{tabular}{|l|l|}
\hline \multirow{3}{*}{ Histórico } & $\begin{array}{l}\text { Submissão: 18/01/2019 } \\
\text { Revisão: 20/04/2020 } \\
\text { Aceite: 24/04/2020 }\end{array}$ \\
\hline \multirow{5}{*}{ Contribuição dos autores } & $\begin{array}{l}\text { Concepção: V. H. B. } \\
\text { Coleta de dados: V. H. B. } \\
\text { Análise de dados: V. H. B.; J. F. L. } \\
\text { Elaboração do manuscrito: V. H. B. } \\
\text { Crítico revisões de conteúdo intelectual } \\
\text { importante: J. F. L. } \\
\text { Aprovação final do manuscrito: J. F. L. }\end{array}$ \\
\hline Consentimento de uso de imagem & \begin{tabular}{l} 
Não se aplica. \\
\hline Aprovação, ética e consentimento
\end{tabular} \\
& $\begin{array}{l}\text { O estudo foi aprovado pelo Ministério Público do } \\
\text { Rio Grande do Norte. Recebeu parecer favorável } \\
\text { do Conselho de Ética em Pesquisa da UFRN } \\
\text { (CEP-UFRN), sob o n 2.445.051. Bem como a } \\
\text { autorização de todos participantes, por meio de } \\
\text { assinatura do termo de consentimento livre e } \\
\text { esclarecido. }\end{array}$ \\
\hline Financiamento & $\begin{array}{l}\text { Pesquisa financiada pelo CNPq na modalidade de } \\
\text { Bolsa de Mestrado, processo n. 132862/2017-4. }\end{array}$ \\
\hline
\end{tabular}

